\title{
Hydroxyl radical induced structural changes of collagen
}

\author{
Helan Xiao ${ }^{\text {a,b,* }}$, Guoping Cai ${ }^{\text {a,**}}$, Mingyao Liu ${ }^{\mathrm{b}}$ \\ ${ }^{a}$ Department of Biological Science and Biotechnology, Cell and Developmental Laboratory, State Key \\ Laboratory of Biomembrane and Membrane Biotechnology, Tsinghua University, Beijing 100084, \\ P.R. China \\ ${ }^{\mathrm{b}}$ Department of Physiology, University of Toronto, Toronto, ON, Canada
}

\begin{abstract}
Extracellular matrix (ECM) plays an important role in cell differentiation, growth, migration and apoptosis. Collagen is the most abundant protein family in vivo, but its function has still not been clearly defined yet. Reactive oxygen species (ROS) have a central role in oxidative cell stress. Electron spin resonance (ESR) spectroscopy indicates that type I collagen could uniquely scavenge hydroxyl radicals in dose- and time-dependent manner; whereas BSA and gelatin (a denatured collagen) have no such an effect. However, the mechanism by which type I collagen scavenges hydroxyl radicals is different from that of GSH, a well-known free radical scavenger. Using a new method, two-dimensional FTIR correlation analysis, for the first time, we show that the order of functional group changes of type I collagen in this process is amide I earlier than amide II than amide III than $-\mathrm{CH}-$ than $\nu(\mathrm{C}=\mathrm{O})$. The results indicates that the structure of the main chain of collagen changed first, followed by more residue group $\nu(\mathrm{C}=\mathrm{O})$ exposed to hydroxyl radicals. The reaction with the carbonyl group in collagen causes the hydroxyl free radicals to be scavenged. Therefore, ECM can effectively scavenge ROS under normal physiological conditions. When the proteins of ECM were denatured in the same way as gelatin, they lost their function as a free radical scavenger. All of these results provide new insight into therapy or prevention of oxidative stress, apoptosis and ageing.
\end{abstract}

Keywords: Free radicals, hydroxyl radicals, Fourier Transform Infrared Spectroscopy (FTIR), Two-Dimensional FourierTransform Infrared Correlation Spectroscopy (2D FTIR), type I collagen

\section{Introduction}

Reactive oxygen species (ROS) such as superoxide anion radical $\left(\mathrm{O}_{2}^{-}\right)$, hydrogen peroxide $\left(\mathrm{H}_{2} \mathrm{O}_{2}\right)$, singlet oxygen $\left({ }^{1} \mathrm{O}_{2}\right)$ and the highly reactive hydroxyl radical $(\cdot \mathrm{OH})[1]$ are well known to be cytotoxic and involved in a wide array of human diseases including cancer [2], malignant diseases [3,4], diabetes [5-7], atherosclerosis [8-10], chronic inflammation [11], viral infection [12], and ischemia-reperfusion injury $[13,14]$. The increased ROS production or changes in intracellular glutathione levels are often involved with pathological changes indicative of a dysregulation of signal cascades or gene expression. In neurodegenerative diseases like Parkinson's, Alzheimer's and amyotrophic lateral sclerosis (ALS), ROS damage has been reported within the specific brain region that undergo selective neurodegeneration [1518]. Protein oxidation has been found in the hippocampus and neocortex of patients with Alzheimer's

\footnotetext{
*Present address: Room TMDT 2-501, Toronto Medical Discovery Tower, MaRS Center, 101 College Street, Toronto, ON M5G 1L7, Canada.

** Corresponding author: Prof. Guoping Cai, Old Building, Room 308, Department of Biological Sciences and Biotechnology, Tsinghua University, Beijing 100084, P.R. China. Tel.: 86106278 3842; Fax: 416581 7504; E-mail: caigp@mail. tsinghua.edu.cn.
} 
disease, Lewy bodies in Parkinson's disease and within the motor neurons in ALS [15-18]. Lipid peroxidation has also been identified in the cortex and hippocampus of patients with Alzheimer's disease, substantia nigra of patients with Parkinson's disease and spinal fluid in patients with ALS [15-18]. It is also shown that ROS can cause neuron and astrocyte cell death through apoptosis or necrosis [15-18].

Extracellular matrix (ECM) plays an important role in cell proliferation [19,20], growth [21], differentiation [22,23], migration [24,25] and apoptosis [26-28]. Recent reports have implied that ECM can influence the survival and apoptosis of several cell lineages including glomerular mesangial cells [29] and fibroblasts. Collagen is the most abundant protein family in human body, but its function is still not clearly identified. Fenton reaction is iron and hydrogen peroxide interaction and generates high reactive ROS- hydroxyl radicals $\left(\mathrm{H}_{2} \mathrm{O}_{2}+\mathrm{Fe}^{2+} \rightarrow \cdot \mathrm{HO}+\mathrm{HO}^{-}+\mathrm{Fe}^{3+}\right)$ [1]. He et al. [30] found that type I collagen can uniquely inhibit lipid peroxidation, reduction of cellular glutathione (GSH) content level, and earlier stage of apoptosis cause by hydroxyl radical. However the mechanism of collagen as a free radical scavenger is largely unknown, due to the inadequate knowledge on the chemical nature of collagen upon free radical simulation and the lack of specific methodology for investigation.

FTIR has been extensively used to study the structure and composition of biological substances such as proteins, lipids, and inorganic compounds. Not only can the compositions be detected, but also the structural configuration, bonding nature, and conformation can be characterized. Recent developments in FTIR provide a possibility to study chemical functional group changes under different external stimulation (temperature, $\mathrm{pH}$, pressure, physical force, etc.) and to characterize structural changes that occur during the process of denaturation such as unfolding and aggregation. This new method, 2D FTIR actually applies 2D cross correlation analyses (a mathematical analysis) of data got from traditional FTIR [31-34]. Then use mathematical tool to do cross correlation analyses to convert to 2D correlation spectra with one synchronous and one asynchronous spectrum. The aim is to emphasize in-phase and out-of-phase correlations between special intensity variations occurring at different wavenumbers that are induced by external stimulation on the samples. 2D FTIR offer a broad potential in protein structure study [35]. Firstly, it can simplify band assignment in complicated biological systems [35]. Secondly, it may establish a potential sequence of events during the physical or chemical procedure [35]. Thus, 2D FTIR seems to be especially suited for protein structure study since it gives rise to broad bands and undergoes multi-steps phenomena when an external perturbation is applied to the biological system.

In the present study, we found that type I collagen worked as a free radical scavenger for hydroxyl radical generated via $\mathrm{Fe}^{2+}$ mediated Fenton reaction in a dose dependent manner. We further studied the structural changes of collagen during scavenging hydroxyl radical by using traditional FTIR spectroscopy and the new method 2D FTIR correlation analysis. For the first time, we found that the order of functional group changes of collagen is - $\mathrm{CH}$ - earlier than Amide I than Amide II than Amide III than residue group $\nu(\mathrm{C}=\mathrm{O})$ in the course of reaction with hydroxyl free radical.

\section{Materials and methods}

\subsection{Materials}

Glutathione (GSH), 5,5-dimethyl-1-pyrroline-1-oxide (DMPO) and bovine serum albumin (BSA) were purchased from Sigma (St. Louis, MO, USA). 


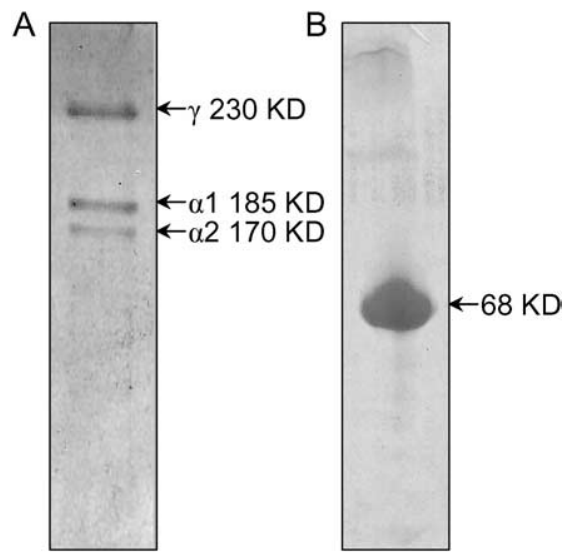

Fig. 1. SDS-PAGE of rat-tail tendon type I collagen and BSA. (A) type I collagen obtained from rat-tail tendon. A sample of $40 \mu \mathrm{g}$ was used for SDS-PAGE. The concentration of the running gel is $11.5 \%$ and stacking gel is $3 \%$. Type I collagen has three bands: $\alpha 2(170 \mathrm{kD}), \alpha 1(185 \mathrm{kD})$, and $\gamma(230 \mathrm{kD})$. (B) BSA. A sample of $40 \mu \mathrm{g}$ was used for SDS-PAGE. The concentration of the running gel is $12.5 \%$ and stacking gel is $3 \%$.

\subsection{Extract type I collagen from rat-tail tendon}

Fresh type I collagen was extracted from rat-tail tendon according to the protocol described by Li et al. [36]. Rat-tail tendon was dissolved in $0.5 \mathrm{M}$ acetic acid for $48 \mathrm{~h}$ at $4^{\circ} \mathrm{C}$. Then it was centrifuged at $4^{\circ} \mathrm{C}, 12,000 \mathrm{rpm}$ for $20 \mathrm{~min}$. The supernatant was salted out by $5 \% \mathrm{NaCl}$ for $48 \mathrm{~h}$ at $4^{\circ} \mathrm{C}$. These steps were repeated five times. The final purified type I collagen sample was dialysis with double distilled water for $48 \mathrm{~h}$ at $4^{\circ} \mathrm{C}$, and then dried at $14 \mathrm{~Pa}$ at $-80^{\circ} \mathrm{C}$ to become powder, and then was stored at $-20^{\circ} \mathrm{C}$. To test the purity of type I collagen sample, SDS-PAGE was performed and shown as single bands after Coomassie Blue R250 staining (Fig. 1A).

\subsection{ESR spectra}

Hydroxyl radicals generated by the $\mathrm{Fe}^{2+}$-mediated Fenton reaction, were detected by spin-trap electron spin resonance (ESR) spectroscopy (Bruker, Germany). $0.1 \mathrm{mM} \mathrm{FeSO}_{4}$ was mixed with $0.6 \mathrm{mM}$ $\mathrm{H}_{2} \mathrm{O}_{2}$ in the presence of $100 \mathrm{mM}$ DMPO, a hydroxyl radical trap reagent, and then the Fenton reaction mixtures were sucked into a silica capillary sample tube. ESR spectrum was scanned at frequency modulation of $100 \mathrm{kHz}$, amplitude modulation of $2 \mathrm{G}, \mathrm{sp}=\mathrm{dB} 10$, with a field of $328 \pm 10 \mathrm{mT}$ using an ER200/D ESR spectroscope (Bruker, Germany). Four ESR peaks of $\cdot \mathrm{OH}$ radicals were observed as shown in Fig. 2A. To investigate the effect of type I collagen, Gelatin, BSA, and GSH on -OH radicals, the time course curves of the second peak from the left of the OH ESR spectra were recorded during a time course of $30 \mathrm{~min}$. The ESR signal was immediately recorded after $100 \mathrm{mM}$ DMPO was added to the reaction mixture.

\subsection{Collagen treated by Fenton reaction}

Type I collagen reacted with $\mathrm{Fe}^{2+}$-mediated Fenton reaction solution for $2 \mathrm{~h}$ at $4{ }^{\circ} \mathrm{C}$ in dark. The $\mathrm{Fe}^{2+}$ mediated Fenton reaction solution is $0.1 \mathrm{mM} \mathrm{FeSO}_{4}$ with different concentration of $\mathrm{H}_{2} \mathrm{O}_{2}$ in the range from $0.1 \mathrm{mM}$ to $0.9 \mathrm{mM}$ (FH1 to FH9). The negative control $\left(0 \mathrm{mM} \mathrm{FeSO}_{4} / 0 \mathrm{mM} \mathrm{H}_{2} \mathrm{O}_{2}\right)(\mathrm{FH} 0)$ and these nine samples were washed with double distilled water for 5 times and then dialysis with double distilled water for $48 \mathrm{~h}$ at $-4^{\circ} \mathrm{C}$, and dried at $-80^{\circ} \mathrm{C}$ at $14 \mathrm{~Pa}$ for $48 \mathrm{~h}$ to become powder. 
A
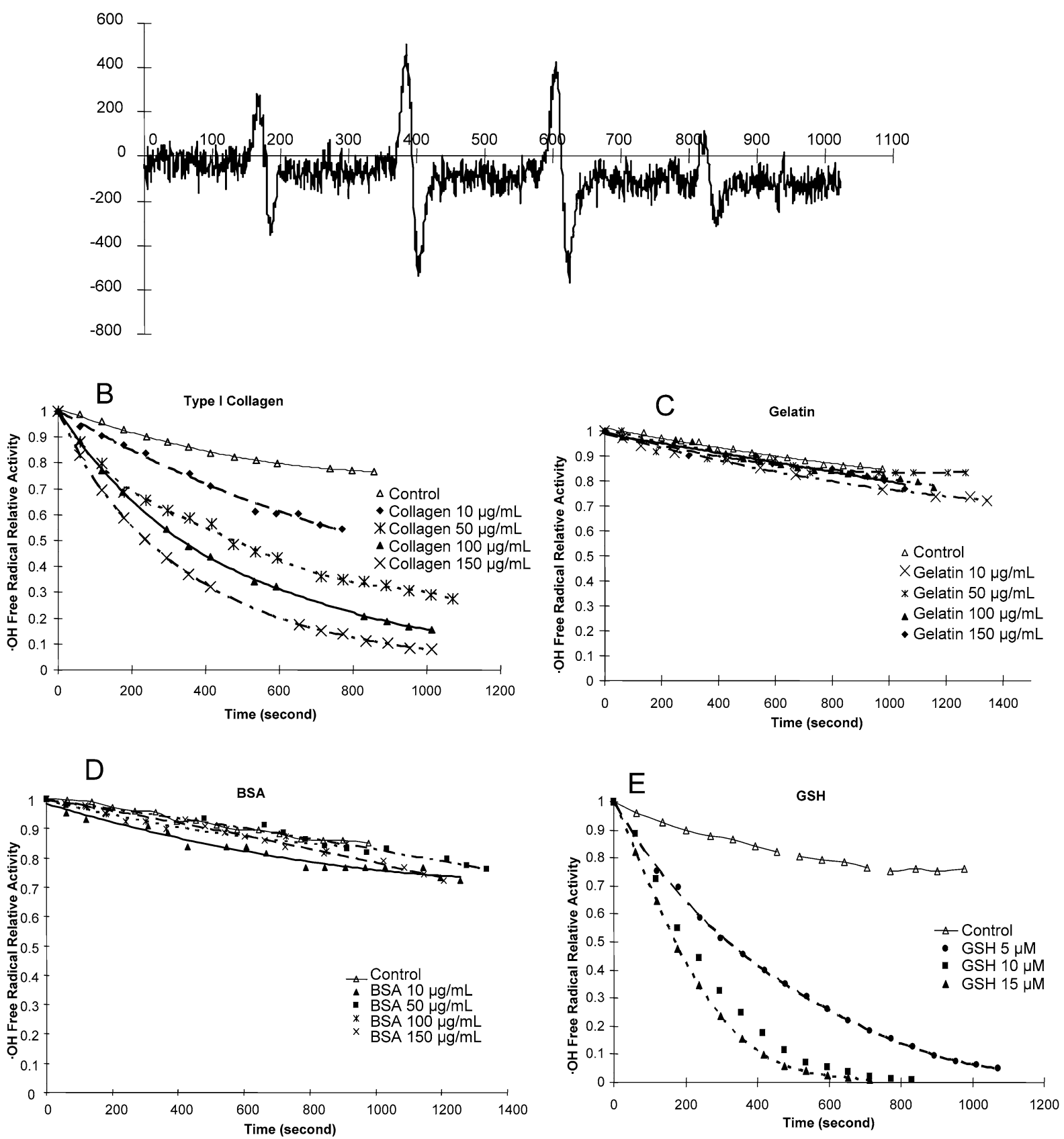

Fig. 2. Type I collagen specifically inhibits $\cdot \mathrm{OH}$ generation in Fenton reaction. (A) ESR signals of $\cdot \mathrm{OH}$ generated by Fenton reaction. The Fenton reaction mixture contained $0.1 \mathrm{mM} \mathrm{FeSO}_{4} / 0.6 \mathrm{mM} \mathrm{H}_{2} \mathrm{O}_{2}$ and $100 \mathrm{mM}$ DMPO. (B-E) Attenuation curves of the second peak from the left of $\cdot \mathrm{OH}$ ESR spectra. The reaction mixture contained $0.1 \mathrm{mM} \mathrm{FeSO} / / 0.6 \mathrm{mM} \mathrm{H}_{2} \mathrm{O}_{2}$ and 100 mM DMPO plus different dose of type I collagen (B), or Gelatin (C), or BSA (D) or GSH (E). Control group in each panel (B-E) only contain $0.1 \mathrm{mM} \mathrm{FeSO}_{4} / 0.6 \mathrm{mM} \mathrm{H}_{2} \mathrm{O}_{2}$ and $100 \mathrm{mM}$ DMPO without any treatments. The measurements were carried out continuously for $30 \mathrm{~min}$. All these in vitro experiments were done triplicate independently. 


\subsection{Infrared spectroscopy}

The infrared spectra of collagen samples, with or without incubation of Fenton reaction solution, were recorded with a Perkin Elmer Spectrum GX FT-IR spectrometer (Perkin Elmer, Wellesley, MA, USA) which equipped with a DTGS detector. The final products of type I collagen treated with Fenton reaction were dialysis with double distilled water for $48 \mathrm{~h}$ at $4^{\circ} \mathrm{C}$, and then dried at $14 \mathrm{~Pa}$ at $-80^{\circ} \mathrm{C}$ for $48 \mathrm{~h}$ to make them become powder. The infrared samples ( $1 \mathrm{mg}$ powder) were evenly mixed with KBR in KBR pellets. The measurements were performed at a resolution of $4 \mathrm{~cm}^{-1}$ and in the range of $400-4000 \mathrm{~cm}^{-1}$. To obtain an acceptable signal-to-noise ratio, 32 scans were accumulated for each sample.

\section{6. $2 D$ FTIR cross correlation analysis}

The spectra got from regular FTIR were transformed into a **.asc file by Perkin Elmer Spectrum Software V3.02, and 2D FTIR cross correlation analyses were performed by using a software developed and described by Yu et al. [37] according to the generalized 2D cross correlation formalism developed and modified by Noda et al. [31-34]. The concentration-averaged spectrum was used as a reference during analysis. Since 2D correlation is an analysis of two independent wave lengths, the cross correlation peaks are represented as pairs $\left(\nu_{1}, \nu_{2}\right)\left(\nu_{1}\right.$ : horizontal, $\nu_{2}$ : vertical) in synchronous and asynchronous plots. In all 2D cross correlation plots, the negative peaks are in pink and shaded, whereas the black and un-shaded peaks are positive. Only the peaks in the 2D cross correlation spectra that are greater than the noise peaks are considered as significant.

\section{Results and discussion}

\subsection{Type I collagen specifically inhibits $\cdot \mathrm{OH}$ generation in Fenton reaction}

To test the effect of collagen on free radical, $\cdot \mathrm{OH}$ radicals were generated by $\mathrm{Fe}^{2+}$-mediated Fenton reaction. The methods for detection of $\cdot \mathrm{OH}$ are based on the introduction of a molecular probe that can successfully competes with reaction mixtures for $\cdot \mathrm{OH}$, forms stable hydroxyl radical-derived analytes. The ESR spin-trapping technique is the most direct method for analysis of radical intermediates. Many spin-trapping agents such as DMPO, POBN, PBN, can direct detect $\cdot \mathrm{OH}$ by forming the ESR-detectable hydroxyl radical-derived nitroxides. The reaction between $\cdot \mathrm{OH}$ and DMPO yields methyl radical $\left(\mathrm{CH}_{3} \cdot\right)$ which can alkylate nitrones via 1,3-addition to ESR-detectable nitroxides. The ESR spectra (Fig. 2A) of DMPO/.OH obtained from Fenton reaction mixtures of $\mathrm{H}_{2} \mathrm{O}_{2}(0.1 \mathrm{mM})$ and $\mathrm{FeSO}_{4}(0.6 \mathrm{mM})$ containing DMPO $(100 \mathrm{mM})$. The signals of $\cdot \mathrm{OH}$ radicals were strapped by $100 \mathrm{mM}$ DMPO. The ESR spectrum of the $\cdot \mathrm{OH}$ radical has four peaks within the field of $328 \pm 10 \mathrm{mT}$ (Fig. 2A). This spectrum was composed of four splitting lines with an intensity ratio of $1: 2: 2: 1$, which typically results from the interactions of an uncoupled electron with a primary nitrogen atom along with a secondary $\beta$-proton.

The time-course curves of the second peak of the $\cdot$ OH ESR spectrum were recorded over $30 \mathrm{~min}$ in order to quantitatively test the inhibitory effect of type I collagen on $\mathrm{OH}$ radicals. In Fig. 2B we observed that type I collagen could dose- dependently inhibit hydroxyl radical generation in $\mathrm{Fe}^{2+}$-mediated Fenton reaction. GSH is a well-known biological free radical scavenger, and it can quench $\cdot \mathrm{OH}$ radicals effectively. In Fig. 2E, GSH significantly inhibited the $\cdot \mathrm{OH}$ radicals in a short period of time. In Figs $2 \mathrm{C}$ and 2D, BSA and gelatin, a well-known denatured collagen, did not significantly reduce the amplitude of ESR signals of $\cdot \mathrm{OH}$ radicals. Therefore, type I collagen has some specific structure or protein residue 
which has a unique function of scavenging hydroxyl free radicals. The inhibitory effect of type I collagen on free radical is also different from GSH. GSH quenched - OH radicals dramatically and rapidly, whereas collagen scavenged hydroxyl radical gradually and gently. In Figs 2B-E, the hydroxyl radical activities decay exponentially. We can use $Y=\mathrm{e}^{A_{1} X+B_{1}}$ fit the curves theoretically. The decay constant, a positive constant used to describe that rate of exponential decay, vary differently among these samples. In Fig. $2 \mathrm{C}$ the decay constant of gelatin is almost no great changes compared to control, the same as in Fig. 2D for BSA. The inhibitory affect of type I collagen and GSH on hydroxyl radicals is different. The decay constant of type I collagen is control group $0.00033,10 \mu \mathrm{g} / \mathrm{ml}$ type I collagen for 0.00081 , $50 \mu \mathrm{g} / \mathrm{ml}$ for $0.00116,100 \mu \mathrm{g} / \mathrm{ml}$ for 0.00183 , and $150 \mu \mathrm{g} / \mathrm{ml}$ for 0.00249759 . The decay constant of GSH is control group for $0.00029,5 \mu \mathrm{M}$ for $0.002796,10 \mu \mathrm{M}$ for 0.00592 , and $15 \mu \mathrm{M}$ for 0.0068 . Halflife $\left(t_{1 / 2}\right)$ is the time it takes for hydroxyl radical to lose half of its relative activity. The half-life of type I collagen is control group for 2100.4 second, $10 \mu \mathrm{g} / \mathrm{ml}$ for 855.8 second, $50 \mu \mathrm{g} / \mathrm{ml}$ for 597.6 second, $100 \mu \mathrm{g} / \mathrm{ml}$ for $378.7 \mathrm{~second}$, and $150 \mu \mathrm{g} / \mathrm{ml}$ for 277.5 second. The half-life of GSH is control group for 2390.2 second, $5 \mu \mathrm{M}$ for 247.9 second, $10 \mu \mathrm{M}$ for 117.1 second, and $15 \mu \mathrm{M}$ for 101.9 second. Lifetime $(\tau)$ is the time it takes for hydroxyl radical to lose its relative activity to $1 / \mathrm{e}$. The lifetime of type I collagen is control group for 3030.3 second, $10 \mu \mathrm{g} / \mathrm{ml}$ for 1234.6 second, $50 \mu \mathrm{g} / \mathrm{ml}$ for 862.1 second, $100 \mu \mathrm{g} / \mathrm{ml}$ for 546.4 second, and $150 \mu \mathrm{g} / \mathrm{ml}$ for 400.4 second. The half-life of GSH is control group for 3448.3 second, $5 \mu \mathrm{M}$ for 357.7 second, $10 \mu \mathrm{M}$ for 168.9 second, and $15 \mu \mathrm{M}$ for 147.1 second. It indicated that type I collagen as extracellular matrix "physiological buffer" can scavenge hydroxyl radicals but also maintain a basal normal level of essential radicals for regular physiological function. These ESR results demonstrate that type I collagen can specifically inhibit the generation and maintenance of .OH radicals in Fenton reaction system.

\subsection{Fenton reaction induces collagen structure changes in amide I and II and residue group of $\nu(C=O)$}

Figure $3 \mathrm{~A}$ is the FTIR spectra of type I collagen at $15^{\circ} \mathrm{C}$. The assignment of major functional groups of collagen is shown in Table 1. The structure changes of collagen induced by Fenton reaction was analyzed

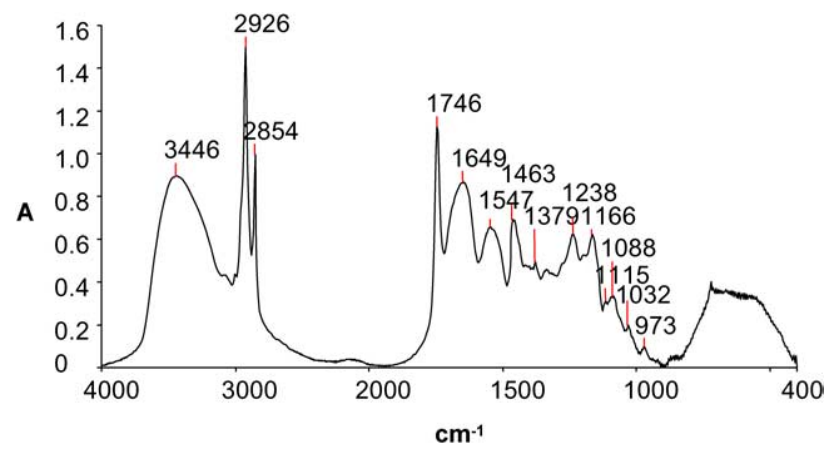

Fig. 3. FTIR spectrum of type I collagen. (A) Type I collagen was scanned with Perkin Elmer Spectrum GX FT-IR spectrometer in the range of $400-4000 \mathrm{~cm}^{-1}$ at $15^{\circ} \mathrm{C}$. The peaks and representative major functional groups are assigned in Table 1 . (B) Type I collagen treated with Fenton reaction solution was scanned with Perkin Elmer Spectrum GX FT-IR spectrometer in the range of $400-4000 \mathrm{~cm}^{-1}$ at $15^{\circ} \mathrm{C}$. The $\mathrm{Fe}^{2+}$-mediated Fenton reaction solution is $0.1 \mathrm{mM} \mathrm{FeSO}_{4}$ with different concentration of $\mathrm{H}_{2} \mathrm{O}_{2}$ in the range from $0.1 \mathrm{mM}$ to $0.9 \mathrm{mM}$ (FH 1 to $\left.\mathrm{FH} 9\right)$. The negative control $\left(0 \mathrm{mM} \mathrm{FeSO} 4 / 0 \mathrm{mM} \mathrm{H}_{2} \mathrm{O}_{2}\right)(\mathrm{FH} 0)$ and these nine samples were washed with double distilled water for 5 times and then dialysis with double distilled water for 48 $\mathrm{h}$ at $4{ }^{\circ} \mathrm{C}$ and frozen and dried at $-40^{\circ} \mathrm{C}$ at $14 \mathrm{~Pa}$ for $48 \mathrm{~h} .1 \mathrm{mg}$ infrared sample was mixed with $\mathrm{KBR}$ in KBR pellet. 
Table 1

Assignments of the major functional groups in type I collagen based on FTIR spectrum

\begin{tabular}{ccc}
\hline Wavenumber $\left(\mathrm{cm}^{-1}\right)$ & Intensity & Assignment \\
\hline 3446 & $\mathrm{~s}$ & $\mathrm{~N}-\mathrm{H}$ \\
2926 & $\mathrm{~s}$ & $\nu_{\alpha s}\left(\mathrm{CH}_{2}\right)$ \\
2854 & $\mathrm{~s}$ & $\nu_{s}\left(\mathrm{CH}_{2}\right)$ \\
1746 & $\mathrm{~s}$ & Residue group $\nu(\mathrm{C}=\mathrm{O})$ \\
1649 & $\mathrm{~s}$ & Amide I \\
1547 & $\mathrm{~s}$ & Amide II \\
1463 & $\mathrm{~s}$ & $\delta(\mathrm{CH})$ \\
1379 & $\mathrm{~m}$ & $\delta\left(\mathrm{CH}_{2}\right)$ \\
1238 & $\mathrm{~m}$ & Amide III
\end{tabular}

Note: s: strong; m: moderate.

with FTIR (Fig. 4). The spectra in the range of $1480 \mathrm{~cm}^{-1}$ to $1770 \mathrm{~cm}^{-1}$ were plotted in Fig. 4A. In Fig. 3B, it showed that $\mathrm{N}-\mathrm{H}$ at $3446 \mathrm{~cm}^{-1}$ increased intensity and shifted to right-hand side gradually upon Fenton reaction treatment. In Fig. 4A, the peak of $\nu(\mathrm{C}=\mathrm{O})$ at $1746 \mathrm{~cm}^{-1}$ moved to left hand side to increase the wave number gradually during Fenton reaction. The amide I $\left(1640 \mathrm{~cm}^{-1}\right)$ moved to right hand side to decrease the wave number gradually whereas the amide II $\left(1547 \mathrm{~cm}^{-1}\right)$ moved to left hand side gradually to increase the wave number and the band became flat in Fenton reaction. It suggests that the collagen might gradually undergo unfolding upon hydroxyl radical stimulation.

From Fig. 3B, it can be noted that intensities of $\nu(\mathrm{C}=\mathrm{O})$ at $1746 \mathrm{~cm}^{-1}, \nu_{\alpha s}\left(\mathrm{CH}_{2}\right)$ at $2926 \mathrm{~cm}^{-1}$, and $\nu_{s}\left(\mathrm{CH}_{2}\right)$ at $2854 \mathrm{~cm}^{-1}$ gradually decrease in a hydroxyl radical dose dependent manner. This result indicates that hydroxyl radical may react with these function groups of collagen. Compared with the control, the spectra intensity of collagen treated with Fenton reaction solution were suppressed in a -OH-dose dependent manner. For example, the peaks of carboxyl group $\nu(\mathrm{C}=\mathrm{O})$ of a residual acetic acid or Asn, Gln amino acid residues at $1746 \mathrm{~cm}^{-1}$, and the peaks of amide $\mathrm{I}\left(1649 \mathrm{~cm}^{-1}\right)$ and amide II $\left(1547 \mathrm{~cm}^{-1}\right)$ decrease gradually with the increasing concentrations of hydroxyl free radical. The 2nd derivative curves of the spectra showed more detailed changes with additional peaks (Fig. 4B), which were not recognized from the original FTIR spectra. The Fourier denovation spectra also revealed more details of structural changes of collagen after treated by Fenton reaction solution; in particular, it is noted that with the higher concentrations of $\mathrm{FeSO}_{4} / \mathrm{H}_{2} \mathrm{O}_{2}$ (FH5 and FH6), the changes were more dramatic compared with lower concentrations of $\mathrm{FeSO}_{4} / \mathrm{H}_{2} \mathrm{O}_{2}$ (Fig. 4C). Interestingly, it also shows that the values of denovation spectra of FH5 group were higher than that in FH6 group in certain ranges of wavelengths.

\section{3. $2 D$ FTIR revealed the order of structural changes of collagen induced by Fenton reaction}

With FTIR, the structural changes of collagen were detected; however the mechanisms and the processes of these changes are still not clear. To further investigate the details of structural changes of collagen induced by Fenton reaction, 2D FTIR correlation analysis spectroscopy was performed. The synchronous and asynchronous spectra of collagen after treatment with Fenton reaction solution in the range of $1480 \mathrm{~cm}^{-1}$ to $1800 \mathrm{~cm}^{-1}$ are shown in Fig. 5A, B. In the synchronous plot (Fig. 5A) there are three autopeaks: $1547 \mathrm{~cm}^{-1}, 1649 \mathrm{~cm}^{-1}$, and $1746 \mathrm{~cm}^{-1}$, at the diagonal positions. They represent amide II, amide I, and residue group $\nu(\mathrm{C}=\mathrm{O})$, respectively. The sensitivity of these functional groups to hydroxyl free radical is residue group of $\nu(\mathrm{C}=\mathrm{O})$ greater than amide II than amide I. There are also 

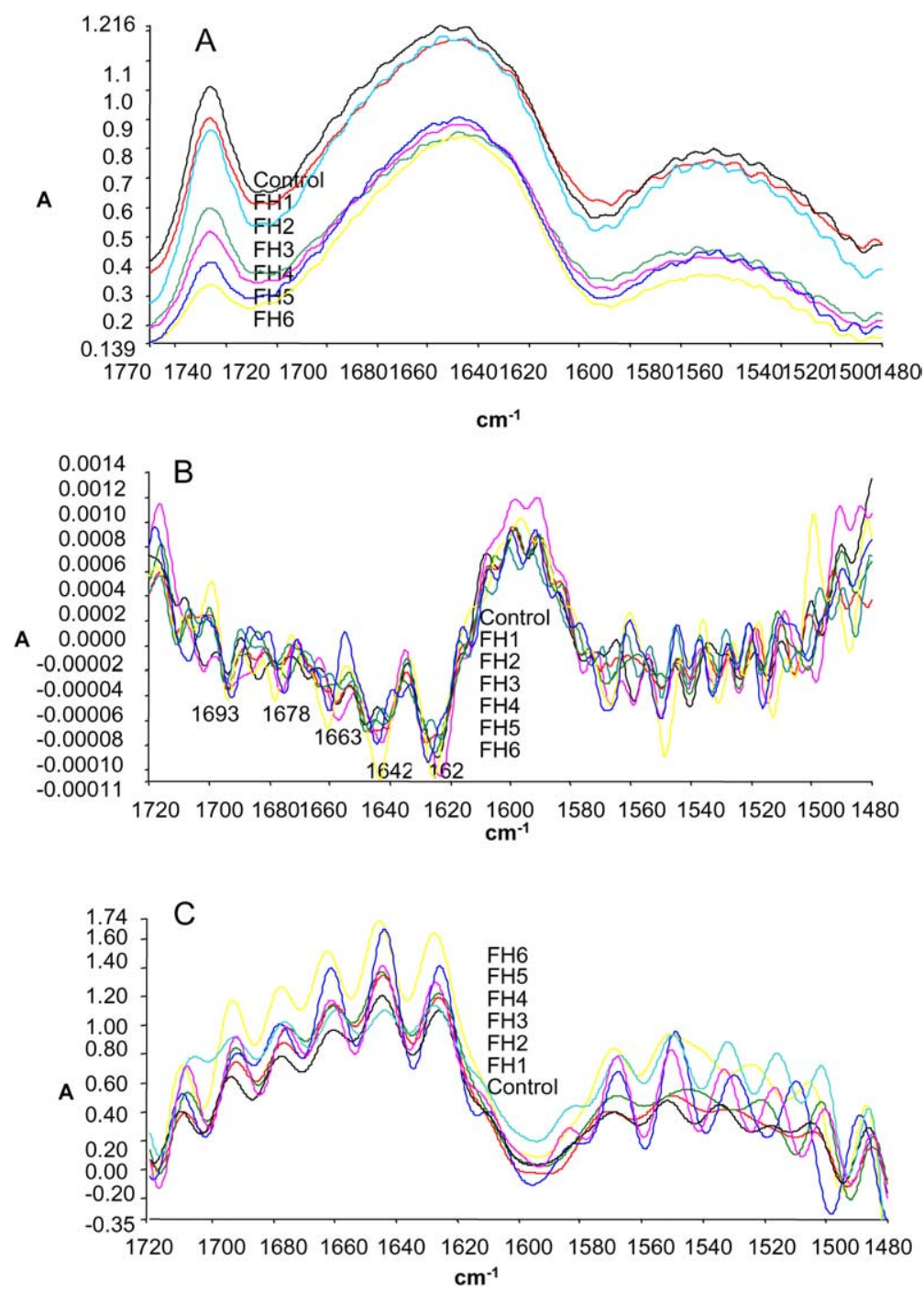

Fig. 4. Fenton reaction induced structural changes of collagen analyzed by FTIR. (A) Control and collagen treated by Fenton reaction were analyzed with FTIR. The spectra in the range of $1480-1770 \mathrm{~cm}^{-1}$ were plotted. (B) The 2nd derivation spectra and $(\mathrm{C})$ Fourier denovation spectra show that collagen treated by different dose of Fenton reaction had different effects on structures of functional groups.

positive cross-peaks at $(1649,1547),(1746,1547)$, and $(1649,1746)$ in Fig. 5A. It means that the following changes are positively correlated: (1) between amide I and amide II, (2) between amide II and the residue group $\nu(\mathrm{C}=\mathrm{O})$, (3) between the residue group of $\nu(\mathrm{C}=\mathrm{O})$ and amide $\mathrm{I}$. In asynchronous plot (Fig. 5B), there are negative cross-peaks at $(1746,1547)$ and $(1746,1649)$. According to 2D FTIR rules [31-34,37], if there is a positive peak in synchronous plot and a positive peak in asynchronous plot, then $\nu_{1}$ changes earlier than $\nu_{2}$; if there is a positive peak in synchronous plot but a negative peak in asynchronous plot, then $\nu_{1}$ changes later than $\nu_{2}$. By the 2D FTIR rules, the order of changes of these functional groups is amide II preceding the residue group of $\nu(\mathrm{C}=\mathrm{O})$ and amide I preceding residue group $\nu(\mathrm{C}=\mathrm{O})$. 


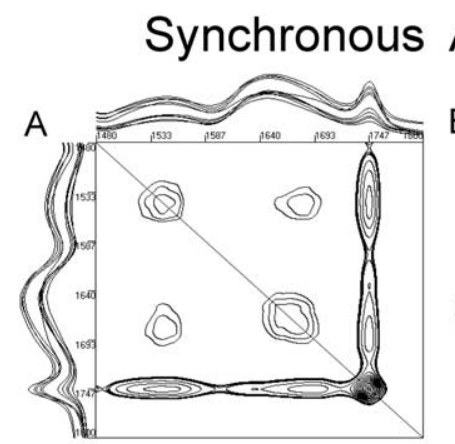

\section{Asynchronous}
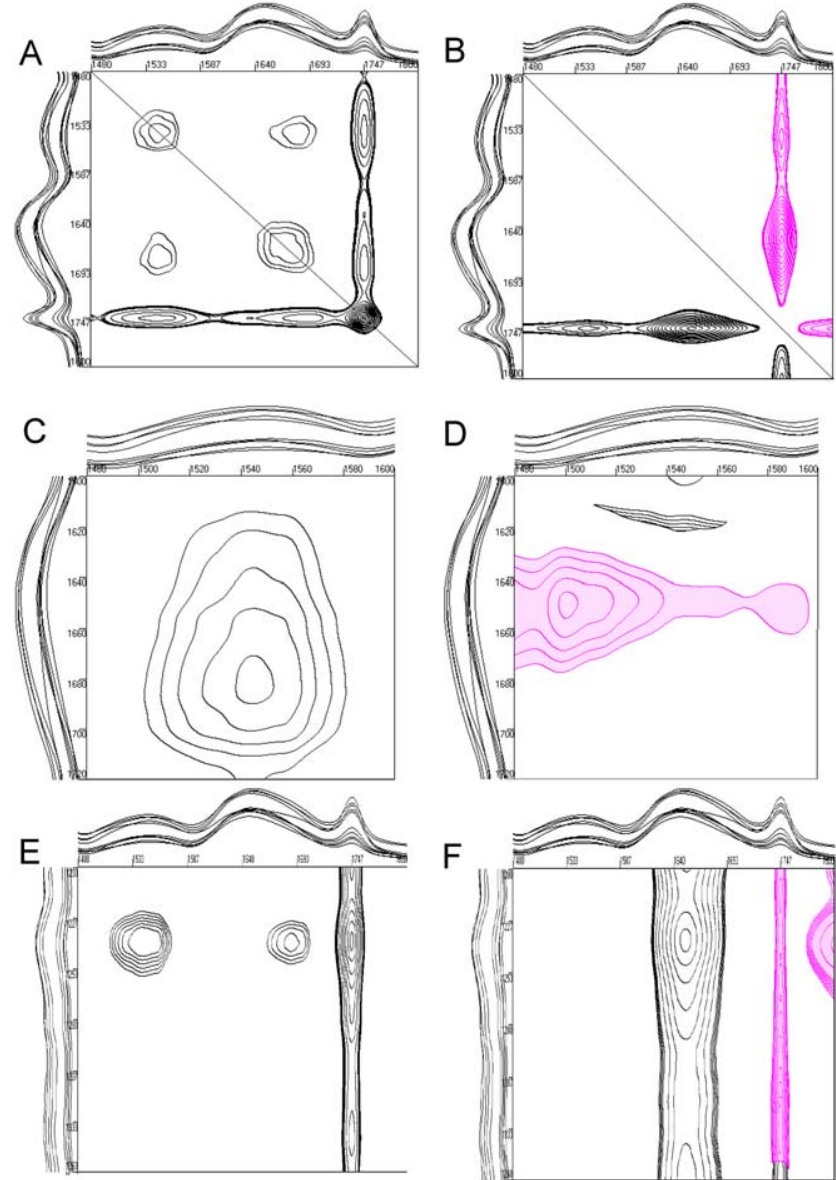

D
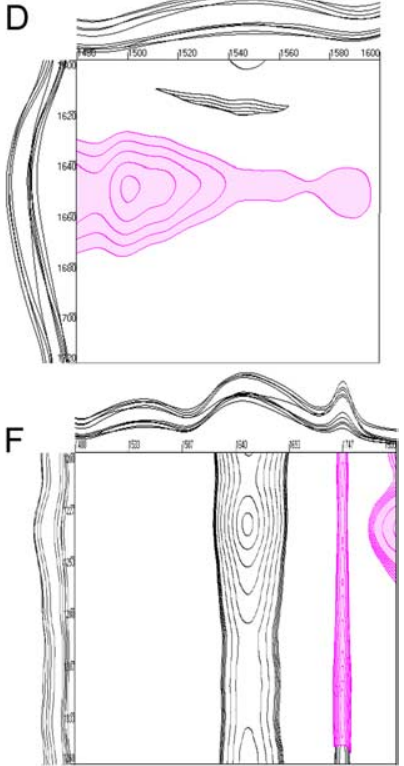

\section{Synchronous Asynchronous}
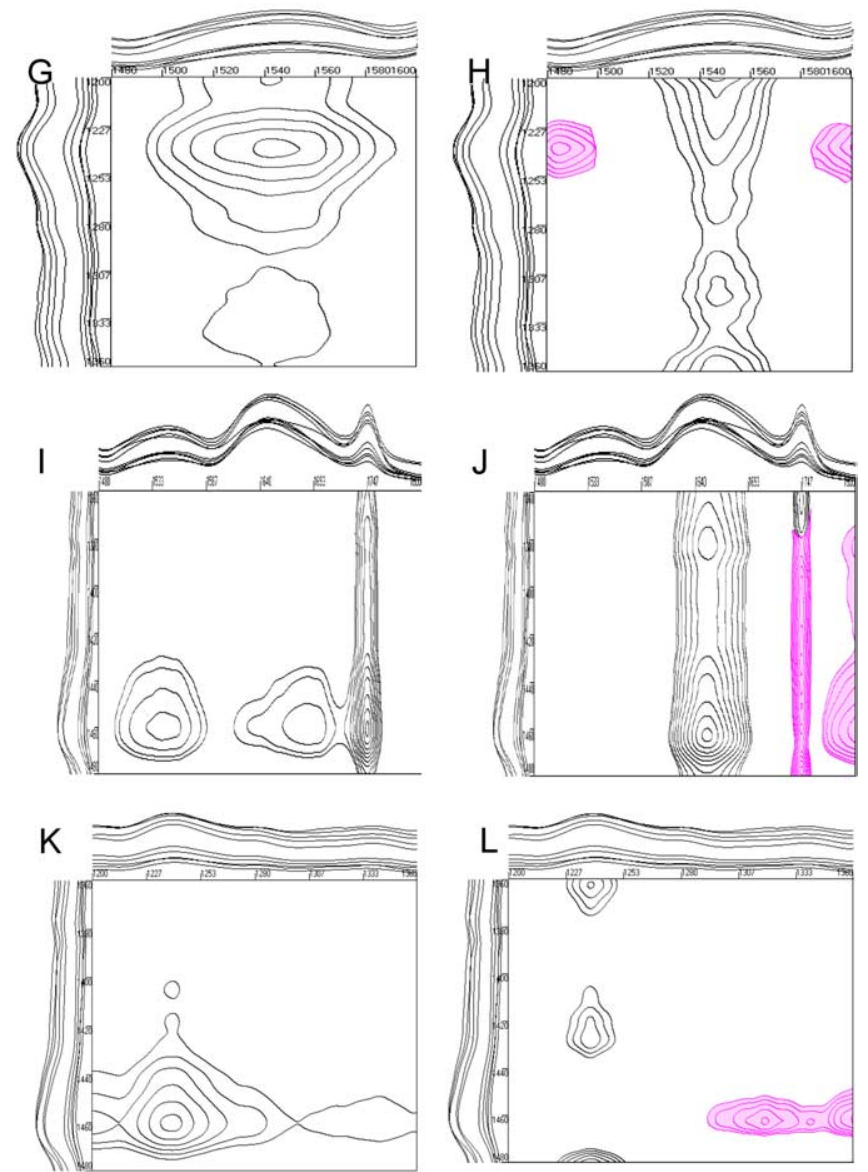

Fig. 5. 2D FTIR analysis of structural changes of collagen induced by Fenton reaction. Control and collagen treated by Fenton reaction were analyzed with 2D FTIR. Synchronous (left) and asynchronous (right) spectra were plotted in two columns. (A, B) both $\nu_{1}$ and $\nu_{2}$ in the range of $1480 \mathrm{~cm}^{-1}$ to $1800 \mathrm{~cm}^{-1}$. (C, D) $\nu_{1}$ in the range of $1480 \mathrm{~cm}^{-1}$ to $1600 \mathrm{~cm}^{-1}$ and $\nu_{2}$ in the range of $1600 \mathrm{~cm}^{-1}$ to $1720 \mathrm{~cm}^{-1}$. (E, F) $\nu_{1}$ in the range of $1480 \mathrm{~cm}^{-1}$ to $1800 \mathrm{~cm}^{-1}$ and $\nu_{2}$ in the range of $1200 \mathrm{~cm}^{-1}$ to $1360 \mathrm{~cm}^{-1}$. (G, H) $\nu_{1}$ in the range of $1480 \mathrm{~cm}^{-1}$ to $1600 \mathrm{~cm}^{-1}$ and $\nu_{2}$ in the range of $1200 \mathrm{~cm}^{-1}$ to $1360 \mathrm{~cm}^{-1}$. (I, J) $\nu_{1}$ in the range of $1480 \mathrm{~cm}^{-1}$ to $1800 \mathrm{~cm}^{-1}$ and $\nu_{2}$ in the range of $1360 \mathrm{~cm}^{-1}$ to $1480 \mathrm{~cm}^{-1}$. (K, L) $\nu_{1}$ in the range of $1200 \mathrm{~cm}^{-1}$ to $1360 \mathrm{~cm}^{-1}$ and $\nu_{2}$ in the range of $1360 \mathrm{~cm}^{-1}$ to $1480 \mathrm{~cm}^{-1}$. Positive peaks are in black and negative peaks are in pink and shaded. 
In order to further analyze the order of changes of other functional groups, we set $\left(\nu_{1}, \nu_{2}\right)$ with different ranges for comparison. Figure $5 \mathrm{C}, \mathrm{D}$ is $\nu_{1}$ in the range of $1480 \mathrm{~cm}^{-1}$ to $1600 \mathrm{~cm}^{-1}$ and $\nu_{2}$ in the range of $1600 \mathrm{~cm}^{-1}$ to $1720 \mathrm{~cm}^{-1}$. In the synchronous plot (Fig. 5C), there is one positive cross peak at (1547, 1681), which means that the amide I and amide II are positively correlated in the process of reaction with hydroxyl radical. In the asynchronous plot (Fig. 5D), a negative peak is found at $(1547,1681)$. Thus, it is indicated that change for amide I precede that of amide II.

Figure $5 \mathrm{EF}$ is $\nu_{1}$ in the range of $1480 \mathrm{~cm}^{-1}$ to $1800 \mathrm{~cm}^{-1}$ and $\nu_{2}$ in the range of $1200 \mathrm{~cm}^{-1}$ to $1360 \mathrm{~cm}^{-1}$. In the synchronous plot (Fig. 5E), there are three positive cross peaks at $(1681,1239)$, $(1547,1239)$ and $(1746,1239)$. It indicates that amide $\mathrm{I}$, amide II, amide III, and $\nu(\mathrm{C}=\mathrm{O})$ is positively correlated. In the asynchronous plot (Fig. 5F), there is a positive peak at $(1681,1239)$ and negative peak at $(1746,1239)$. According to the 2D FTIR rule, the order of functional group changes is given by amide I earlier than amide III than $\nu(\mathrm{C}=\mathrm{O})$.

Figure $5 \mathrm{GH}$ is the synchronous and asynchronous spectrum with $\nu_{1}$ in the range of $1480 \mathrm{~cm}^{-1}$ to $1600 \mathrm{~cm}^{-1}$ and $\nu_{2}$ in the range of $1200 \mathrm{~cm}^{-1}$ to $1360 \mathrm{~cm}^{-1}$. In the synchronous plot (Fig. 5G), there is a positive cross peak at $(1547,1239)$, which shows that amide II and amide III are positively correlated. In the asynchronous plot (Fig. 5H), a positive peak is found at $(1547,1239)$. Hence the order of functional groups changes is amide II preceding amide III.

Figure 5IJ is $\nu_{1}$ in the range of $1480 \mathrm{~cm}^{-1}$ to $1800 \mathrm{~cm}^{-1}$ and $\nu_{2}$ in the range of $1360 \mathrm{~cm}^{-1}$ to $1480 \mathrm{~cm}^{-1}$. In the synchronous plot (Fig. 5I), there are three positive peaks at $(1547,1459),(1681$, $1459)$ and $(1746,1459)$, which show that the functional group changes of amide II and - $\mathrm{CH}-$, amide I and $-\mathrm{CH}-, \nu(\mathrm{C}=\mathrm{O})$ and $-\mathrm{CH}-$, are positively correlated. In the asynchronous plot (Fig. 5J), a positive peak is located at $(1681,1459)$ and a negative peak at $(1746,1459)$. Thus, the order of functional group changes is amide I preceding $-\mathrm{CH}$ - preceding $\nu(\mathrm{C}=\mathrm{O})$.

Figure $5 \mathrm{~K}, \mathrm{~L}$ is with $\nu_{1}$ in the range of $1200 \mathrm{~cm}^{-1}$ to $1360 \mathrm{~cm}^{-1}$ and $\nu_{2}$ in the range of $1360 \mathrm{~cm}^{-1}$ to $1480 \mathrm{~cm}^{-1}$. In the synchronous plot (Fig. 5K), there is a positive peak at $(1239,1459)$, which indicated that the functional group changes of amide III and $-\mathrm{CH}$ - are positively correlated. In the asynchronous plot (Fig. 5L), there is a negative peak at $(1239,1459)$. So the order of functional group changes is amide III earlier than -CH-.

All these results of correlation analyses were presented as Fig. 5A-L, and summarized in Table 2. Taken together, these data indicate that upon hydroxyl free radical stimulation, the order of functional group changes of type I collagen is amide I earlier than amide II than amide III than $-\mathrm{CH}-$ than $\nu(\mathrm{C}=\mathrm{O})$.

\section{Conclusion}

ECM provides a structural framework to support cells and maintains cellular functions by mediating cell-cell or cell-ECM interactions. ECM is composed of collagen, elastin, fibronectin, proteoglycans, and other molecules. Collagen is the main protein of ECM and connective tissue in animals and the most abundant protein in mammals, making up about $40 \%$ of the total. It is one of the long, fibrous structural proteins whose functions are quite different from those of globular proteins such as enzymes. Collagen has an unusual amino acid composition and sequence. Gly is found at almost every third residue, and collagen contains large amounts of Pro. A distinctive feature of collagen is the regular arrangement of amino acids in each of the three chains of these collagen subunits. The sequence often follows the pattern Gly-X-Pro or Gly-X-Hypro, where X may be any of various other amino acid residues. Such high Gly and regular repetitions are never found in globular proteins like BSA. He et al. [30] showed 
Table 2

Summary of results from 2D FTIR correlation analysis spectroscopy

\begin{tabular}{ccccc}
\hline Cross peaks & $\begin{array}{c}\text { Synchronous } \\
\text { spectra }\end{array}$ & $\begin{array}{c}\text { Asynchronous } \\
\text { spectra }\end{array}$ & $\begin{array}{c}\text { Order of } \\
\text { changes }\end{array}$ & $\begin{array}{c}\text { Order of functional groups } \\
\text { changes }\end{array}$ \\
\hline$(1746,1677)$ & + & - & $1677>1746$ & Amide I $>\nu(\mathrm{C}=\mathrm{O})$ \\
$(1746,1547)$ & + & - & $1547>1746$ & Amide II $>\nu(\mathrm{C}=\mathrm{O})$ \\
$(1544,1681)$ & + & - & $1681>1544$ & Amide I $>$ Amide II \\
$(1683,1238)$ & + & + & $1683>1238$ & Amide I $>$ Amide III \\
$(1746,1238)$ & + & - & $1238>1746$ & Amide III $>\nu(\mathrm{C}=\mathrm{O})$ \\
$(1543,1239)$ & + & + & $1543>1239$ & Amide II $>$ Amide III \\
$(1687,1459)$ & + & - & $1687>1459$ & Amide I $>-\mathrm{CH}-$ \\
$(1746,1460)$ & + & + & $1460>1746$ & $-\mathrm{CH}->\nu(\mathrm{C}=\mathrm{O})$ \\
$(1239,1460)$ & + & $1239>1460$ & Amide III $>-\mathrm{CH}-$ \\
& Amide I $>$ Amide II $>$ Amide III $>-\mathrm{CH}->\nu(\mathrm{C}=\mathrm{O})$ & \\
\hline
\end{tabular}

Note: >: earlier than.

that type I collagen inhibited the reduction of cellular GSH concentration caused by hydroxyl radical. Whether ECM or collagen is involved in the intracellular signal pathway of hydroxyl radical is still not clearly identified. Figure 2 shows type I collagen can scavenge hydroxyl radical dose dependently in vitro. However, gelatin (denatured collagen) and BSA have no such function. Therefore, type I collagen has the unique anti-oxidant and anti-apoptotic role of scavenging hydroxyl radical.

From the FTIR spectra of type I collagen, the residue group $\nu(C=O)\left(1746 \mathrm{~cm}^{-1}\right)$ gradually disappear when collagen is scavenging hydroxyl radical (Figs 3B and 4A). Amide I has band shift toward lower wavenumbers, whereas the amide II gradually become flat (Fig. 4A). From 2D FTIR analysis, when hydroxyl radicals react with type I collagen, the order of functional group is Amide I earlier than amide II than amide III than $-\mathrm{CH}-$ than $\nu(\mathrm{C}=\mathrm{O})$. Hawkins et al. [38] indicated that the interaction of collagen with hydroxyl radicals occurred at a specific site, for example, a double-sided chain $\left(\cdot \mathrm{CHR}^{\prime} \mathrm{R}^{\prime \prime}\right)$, and $\alpha$-carbon $[\cdot \mathrm{C}(\mathrm{R})(\mathrm{NH}-) \mathrm{CO}-, \mathrm{R}=$ side-chain $]$ radicals. Residue group $\nu(\mathrm{C}=\mathrm{O})$ is mainly in side chain residue of collagen. If the $\mathrm{X}$ on collagen is Asn, or $\mathrm{Gln}$, its residue group $\nu(\mathrm{C}=\mathrm{O})$ will probably react with hydroxyl radical. Since BSA is a globular protein, its residues containing $\nu(C=O)$ are embed into inside of the protein. Thus, they cannot react effectively with the hydroxyl radical. The three chains of type I collagen have around $11.13 \%$ of these four types of amino acids containing $\nu(\mathrm{C}=\mathrm{O})$ on its residue chain in total. Juszczak [39] reported that the FTIR spectra of insoluble tendon type I collagen has a strong, sharp peak at $1746 \mathrm{~cm}^{-1}$, which attributed to type I $\beta$-turns but has also been found in the FTIR amide I band for other proteins with polyproline II secondary structure. The three chains of type I collagen contain around $34.62 \%$ of Pro containing $\nu(\mathrm{C}=\mathrm{O})$ on its residue chain in total. Our lab has focused on the role of extracellular matrix in human diseases. We ever did FTIR for multiple collagen samples, such as type I collagen (not acid soluble) (Sigma, Cat \# C-9879), type I collagen (acid soluble) (Sigma, Cat \# C-9791), type I collagen (Sigma, C-3511), fresh human collagen extracted from human umbilical cords, fresh normal rat-tail tendon collagen, fresh normal rat lung collagen, fresh normal rat stomach collagen, fresh silicosis rat lung collagen, etc. Almost all of these samples have a sharp strong band at $1746 \mathrm{~cm}^{-1}$. Interestingly, we also found the intensity of the $1746 \mathrm{~cm}^{-1}$ peak is weaker in the lung collagen samples from rats with silicosis lung disease (unpublished data). Due to collagen is a long fibrous protein, it has more residues containing $\nu(\mathrm{C}=\mathrm{O})$ exposed to outside and they can react with hydroxyl radical. In the course of type I collagen scavenge hydroxyl radicals, the structure of the main chain of collagen first changed, which suggested protein unfolding, and then more residue group $\nu(\mathrm{C}=\mathrm{O})$ 
exposed to outside hydroxyl radicals. Residue group $\nu(\mathrm{C}=\mathrm{O})$ has a central role in scavenge hydroxyl radicals, but it is the last functional group to undergo structural change. The reaction mechanism of collagen and GSH with hydroxyl radicals is naturally different. Gelatin, a denatured collagen, did not have such a function. Therefore, ECM can effectively scavenge ROS at normal physiological condition. But if the proteins of ECM denatured like degradation and glycosylation in diabetes complications, they lost such function as a free radical scavenger. Hence, the excessive free radicals cause cell to apoptosis and disease and ageing. All these provide new insight into therapy or prevention of oxidative stress for future drug discovery.

\section{Acknowledgements}

The authors would like to thank Dr. Suqin Sun and Dr. Qun Zhou in the Department of Chemistry in Tsinghua University (Beijing, P.R. China) for very helpful discussion and technical assistance.

\section{References}

[1] W.A. Pryor, K.N. Houk, C.S. Foote, J.M. Fukuto, L.J. Ignarro, G.L. Squadrito and K.J. Davies, Free radical biology and medicine: it's a gas, man!, Am. J. Physiol. Regul. Integr. Comp. Physiol. 291 (2006), R491-511.

[2] J. Glover, Free radical biology: a paradox in cancer research, J. Natl. Cancer Inst. 82 (1990), 902-903.

[3] V.I. Ershov, P.F. Litvitskii and B. Kochkareva Iu, [Free radical peroxidation processes and cardiotoxicity in treatment of malignant lymphomas], Klin. Med. (Mosk.) 84 (2006), 47-51.

[4] I.A. Medianik and A.P. Fraerman, [Free radical processes in the etiology, pathogenesis, and treatment of malignant tumors of the brain], Zh. Vopr. Neirokhir. Im. N. N. Burdenko (2005), 39-43.

[5] M. Mohora, B. Virgolici, F. Paveliu, D. Lixandru, C. Muscurel and M. Greabu, Free radical activity in obese patients with type 2 diabetes mellitus, Rom. J. Intern. Med. 44 (2006), 69-78.

[6] M. Mrowicka, [Free-radical reactions in diabetes mellitus], Pol. Merkur. Lekarski 19 (2005), 571-576.

[7] T. Tabatabaie, A. Vasquez-Weldon, D.R. Moore and Y. Kotake, Free radicals and the pathogenesis of type 1 diabetes: beta-cell cytokine-mediated free radical generation via cyclooxygenase-2, Diabetes 52 (2003), 1994-1999.

[8] T.A. Okabe, C. Kishimoto, K. Shimada, T. Murayama, M. Yokode and T. Kita, Effects of MCI-186 (edaravone), a novel free radical scavenger, upon experimental atherosclerosis in apolipoprotein E-deficient mice, Circ. J. 70 (2006), 12161219.

[9] H. Xi, M. Akishita, K. Nagai, W. Yu, H. Hasegawa, M. Eto, K. Kozaki and K. Toba, Potent free radical scavenger, edaravone, suppresses oxidative stress-induced endothelial damage and early atherosclerosis, Atherosclerosis (2006).

[10] B.J. Wu, K. Kathir, P.K. Witting, K. Beck, K. Choy, C. Li and K.D. Croft, T.A. Mori, D. Tanous, M.R. Adams, A.K. Lau and R. Stocker, Antioxidants protect from atherosclerosis by a heme oxygenase-1 pathway that is independent of free radical scavenging, J. Exp. Med. 203 (2006), 1117-1127.

[11] D.E. Auer, J.C. Ng and A.A. Seawright, Free radical oxidation products in plasma and synovial fluid of horses with synovial inflammation, Aust. Vet. J. 70 (1993), 49-52.

[12] A. Basu, P.K. Sehajpal, J.S. Ogiste and H.M. Lander, Targeting cysteine residues of human immunodeficiency virus type 1 protease by reactive free radical species, Antioxid. Redox Signal 1 (1999), 105-112.

[13] J. McCormick, S.P. Barry, A. Sivarajah, G. Stefanutti, P.A. Townsend, K.M. Lawrence, S. Eaton, R.A. Knight, C. Thiemermann, D.S. Latchman and A. Stephanou, Free radical scavenging inhibits STAT phosphorylation following in vivo ischemia/reperfusion injury, FASEB J. 20 (2006), 2115-2117.

[14] C.N. Liu, C. Yang, X.Y. Liu and S. Li, In vivo protective effects of urocortin on ischemia-reperfusion injury in rat heart via free radical mechanisms, Can. J. Physiol. Pharmacol. 83 (2005), 459-465.

[15] J.K. Andersen, Oxidative stress in neurodegeneration: cause or consequence?, Nat. Med. 10 (Suppl.) (2004). S18-25.

[16] H.F. Poon, V. Calabrese, G. Scapagnini and D.A. Butterfield, Free radicals and brain aging, Clin. Geriatr. Med. 20 (2004), 329-359.

[17] H.F. Poon, V. Calabrese, G. Scapagnini and D.A. Butterfield, Free radicals: key to brain aging and heme oxygenase as a cellular response to oxidative stress, J. Gerontol. A. Biol. Sci. Med. Sci. 59 (2004), 478-493.

[18] G. Barja, Free radicals and aging, Trends Neurosci. 27 (2004), 595-600. 
[19] K. Bijian, T. Takano, J. Papillon, A. Khadir and A.V. Cybulsky, Extracellular matrix regulates glomerular epithelial cell survival and proliferation, Am. J. Physiol. Renal Physiol. 286 (2004), F255-266.

[20] S.J. Hirst, C.H. Twort and T.H. Lee, Differential effects of extracellular matrix proteins on human airway smooth muscle cell proliferation and phenotype, Am. J. Respir. Cell. Mol. Biol. 23 (2000), 335-344.

[21] P.A. Eccleston, D.J. Gunton and D.H. Silberberg, Requirements for brain cell attachment, survival and growth in serumfree medium: effects of extracellular matrix, epidermal growth factor and fibroblast growth factor, Dev. Neurosci. 7 (1985), 308-322.

[22] K. Okumoto, T. Saito, E. Hattori, J.I. Ito, A. Suzuki, K. Misawa, R. Ishii, T. Karasawa, H. Haga, M. Sanjo, T. Takeda, K. Sugahara, K. Saito, H. Togashi and S. Kawata, Differentiation of rat bone marrow cells cultured on artificial basement membrane containing extracellular matrix into a liver cell lineage, J. Hepatol. 43 (2005), 110-116.

[23] C.O. Olsen, B.E. Isakson, G.J. Seedorf, R.L. Lubman and S. Boitano, Extracellular matrix-driven alveolar epithelial cell differentiation in vitro, Exp. Lung Res. 31 (2005), 461-482.

[24] E.W. Raines, The extracellular matrix can regulate vascular cell migration, proliferation, and survival: relationships to vascular disease, Int. J. Exp. Pathol. 81 (2000), 173-182.

[25] R. Shimizu-Hirota, H. Sasamura, M. Kuroda, E. Kobayashi, M. Hayashi and T. Saruta, Extracellular matrix glycoprotein biglycan enhances vascular smooth muscle cell proliferation and migration, Circ. Res. 94 (2004), 1067-1074.

[26] L. Delgado, E.R. Parra and V.L. Capelozzi, Apoptosis and extracellular matrix remodelling in human silicosis, Histopathology 49 (2006), 283-289.

[27] G. Oktem, S. Vatansever, S. Ayla, A. Uysal, S. Aktas, B. Karabulut and A. Bilir, Effect of apoptosis and response of extracellular matrix proteins after chemotherapy application on human breast cancer cell spheroids, Oncol. Rep. 15 (2006), 335-340.

[28] F. Vasaturo, C. Malacrino, E. Sallusti, G. Coppotelli, P. Birarelli, A. Giuffrida, L. Albonici, L. Simonelli, A. Modesti, M. Modesti and S. Scarpa, Role of extracellular matrix in regulation of staurosporine-induced apoptosis in breast cancer cells, Oncol. Rep. 13 (2005), 745-750.

[29] A. Nagler, A. Katz, H. Aingorn, H.Q. Miao, R. Condiotti, O. Genina, M. Pines and I. Vlodavsky, Inhibition of glomerular mesangial cell proliferation and extracellular matrix deposition by halofuginone, Kidney Int. 52 (1997), 1561-1569.

[30] Y. He, J. Chen, J. Ren, G. Wang and G. Cai, Type I collagen inhibits hydroxyl radical-induced apoptosis, J. Biochem. (Tokyo) 132 (2002), 373-379.

[31] I. Noda, A.E. Dowrey and C. Marcott, Two-dimensional infrared (2d Ir) spectroscopy - a new tool for interpreting infraredspectra, Mikrochim. Acta 1 (1988), 101-103.

[32] I. Noda, 2-Dimensional infrared (2d Ir) spectroscopy - theory and applications, Appl. Spectrosc. 44 (1990), 550-561.

[33] I. Noda, A.E. Dowrey and C. Marcott, 2-Dimensional infrared (2d Ir) spectroscopy, Abstr. Pap. Am. Chem. S. 202 (1991), 117-Phys.

[34] I. Noda, A.E. Dowrey and C. Marcott, Recent developments in 2-dimensional infrared (2d-Ir) correlation spectroscopy, Appl. Spectrosc. 47 (1993), 1317-1323.

[35] T. Lefevre, K. Arseneault and M. Pezolet, Study of protein aggregation using two-dimensional correlation infrared spectroscopy and spectral simulations, Biopolymers 73 (2004), 705-715.

[36] Y.H. Li, J.C. Yue and G.P. Cai, Fluorescence characterization of type I collagen from normal and silicotic rats and its quenching dynamics induced by hypocrellin B, Biopolymers 42 (1997), 219-226.

[37] Z.W. Yu, J. Liu and I. Noda, Effect of noise on the evaluation of correlation coefficients in two-dimensional correlation spectroscopy, Appl. Spectrosc. 57 (2003), 1605-1609.

[38] C.L. Hawkins and M.J. Davies, Oxidative damage to collagen and related substrates by metal ion/hydrogen peroxide systems: random attack or site-specific damage?, Biochim. Biophys. Acta 1360 (1997), 84-96.

[39] L.J. Juszczak, Comparative vibrational spectroscopy of intracellular tau and extracellular collagen I reveals parallels of gelation and fibrillar structure, The Journal of Biological Chemistry 279 (2004), 7395-7404. 


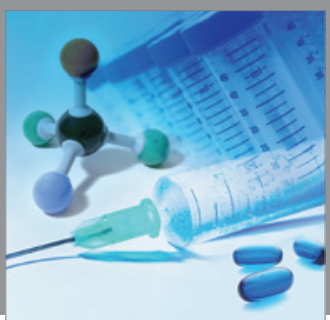

International Journal of

Medicinal Chemistry

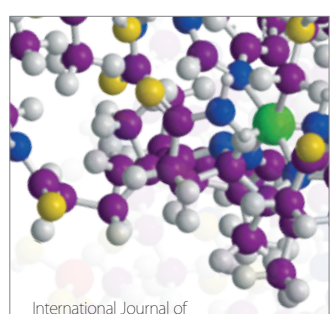

Carbohydrate Chemistry

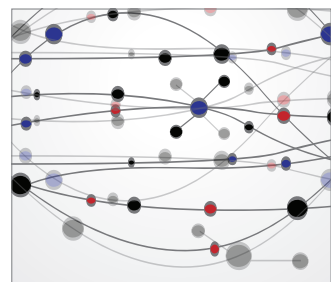

The Scientific World Journal
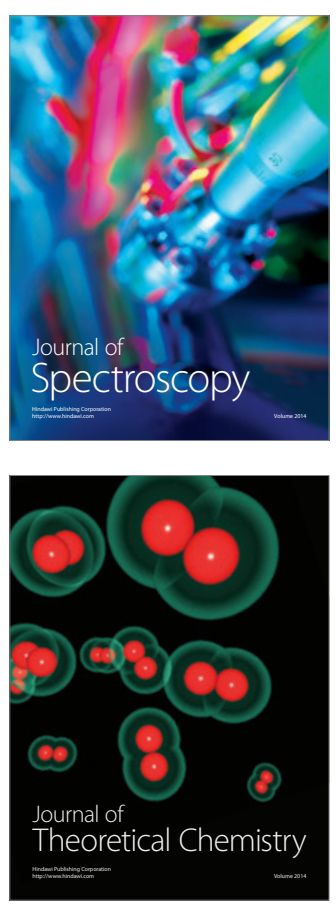
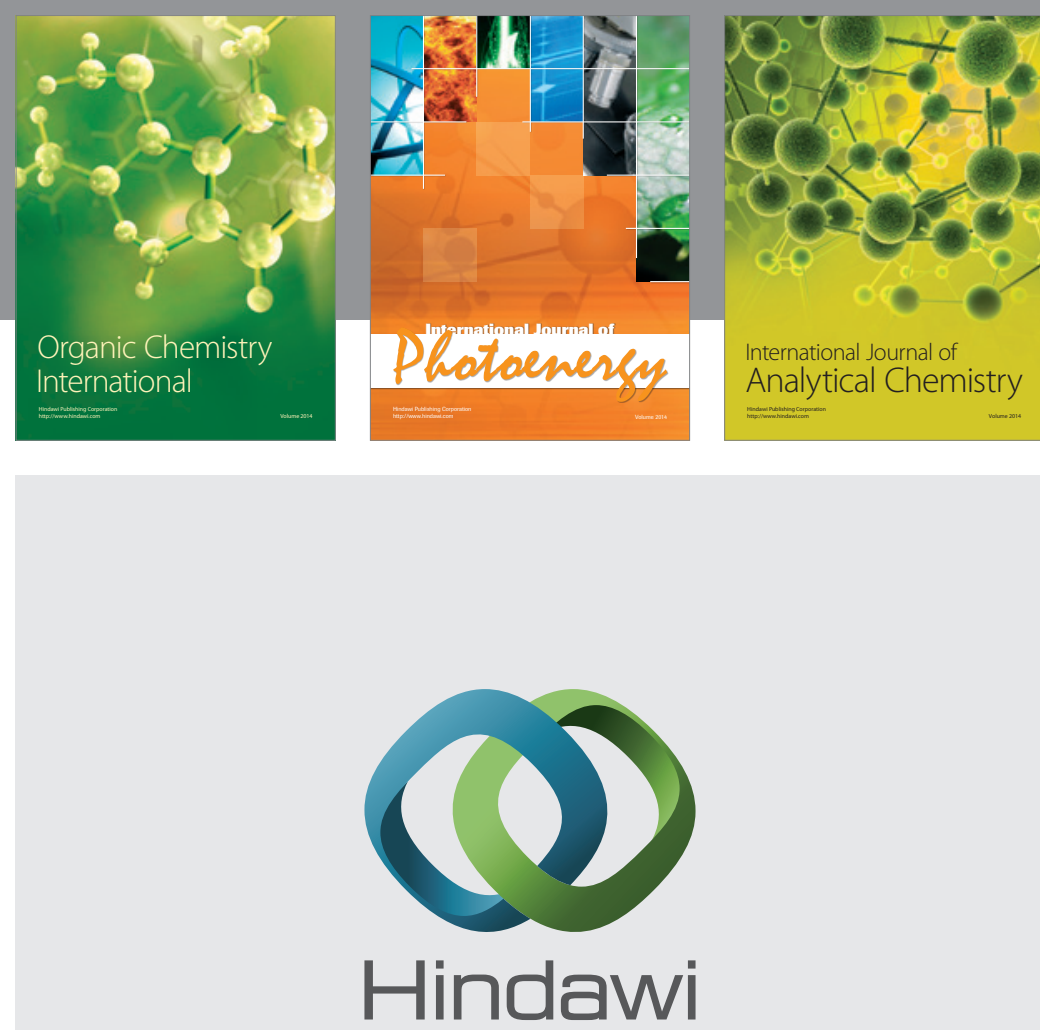

Submit your manuscripts at

http://www.hindawi.com
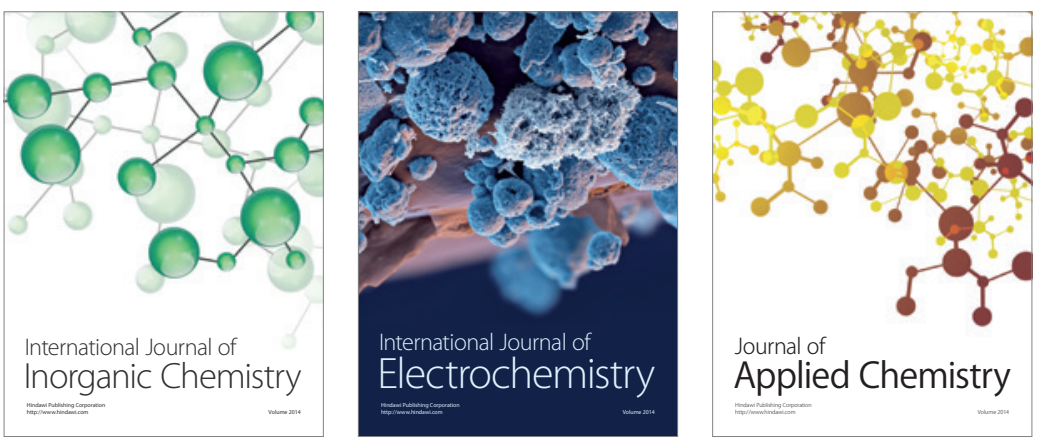

Journal of

Applied Chemistry
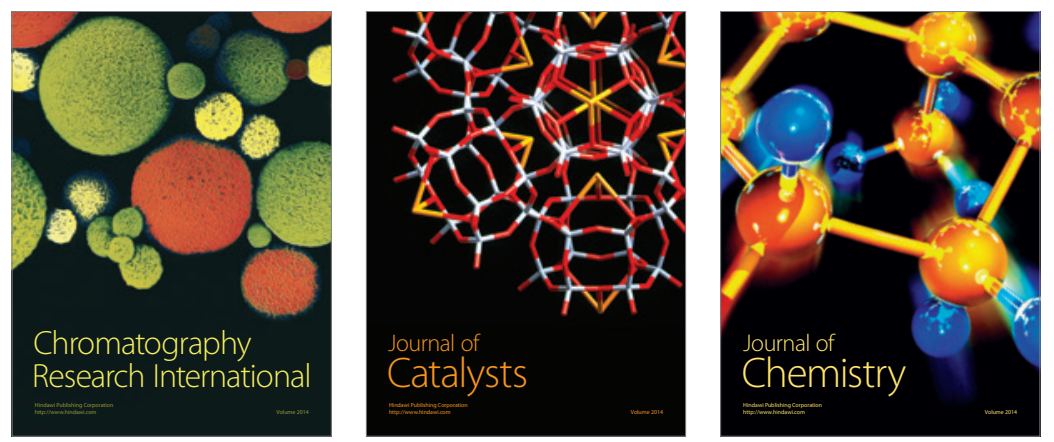
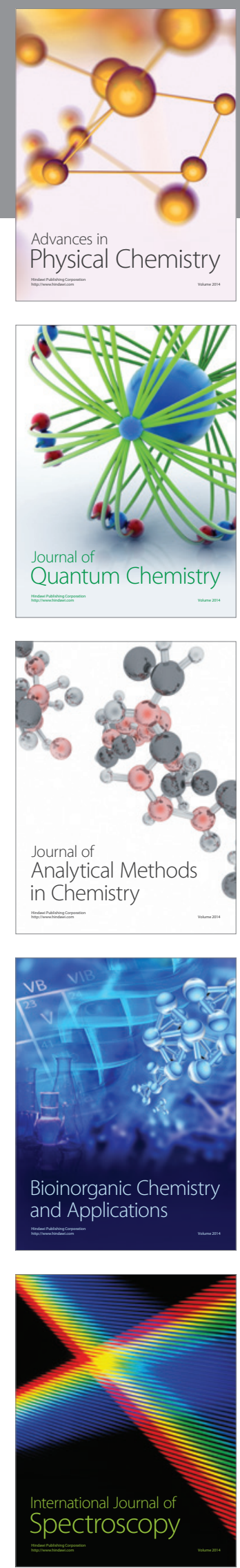